RESEARCH REPORT

\title{
COMPARING THE EFFICACY OF UPPER TRAPEZIUS KINESIOTAPING AND STRETCHING EXERCISES IN PATIENTS WITH MECHANICAL NECK ACHE
}

\begin{abstract}
BACKGROUND AND AIM

Globally, around one third of population is suffering from persistent neck pain and it is considered as 4th important source of disability in the population. Several treatment protocols are available now a day to facilitate patient recovery. Therefore, the aim of this study is to identify the effects of kinesiotaping in improving neck pain, upper trapezius muscle strength and functional disability.
\end{abstract}

\section{STUDY DESIGN}

Randomized controlled trial

\section{SAMPLE SIZE}

68 participants were recruited for the study.

\section{METHODOLOGY}

All participants of age 18-40 years were assessed using assessment Performa. Pain intensity, upper trapezius muscle strength and Neck disability index were measured at baseline and after treatment sessions. Group A comprised of 34 participant, received Kinesiotaping and conventional physical therapy treatment whereas, equal number of participants were recruited in Group B that received upper trapezius stretching and conventional physical therapy.

\section{RESULT}

The study revealed that both interventions (Kinesiotaping and stretching) were effective i.e., <0.05 in improving pain intensity, muscle strength and functional disability in patients with mechanical neck ache but significant improvement were recorded in group treated with kinesiotaping.

\section{CONCLUSION}

The study concluded that both interventions are effective in improving pain intensity, muscle strength and neck disability index but kinesiotaping is more beneficial than stretching among patient with mechanical neck ache.

\section{KEYWORDS}

Neck ache, Kinesiotape, Stretching exercises, Pain scale, Muscle strength, Neck disability index (NDI).

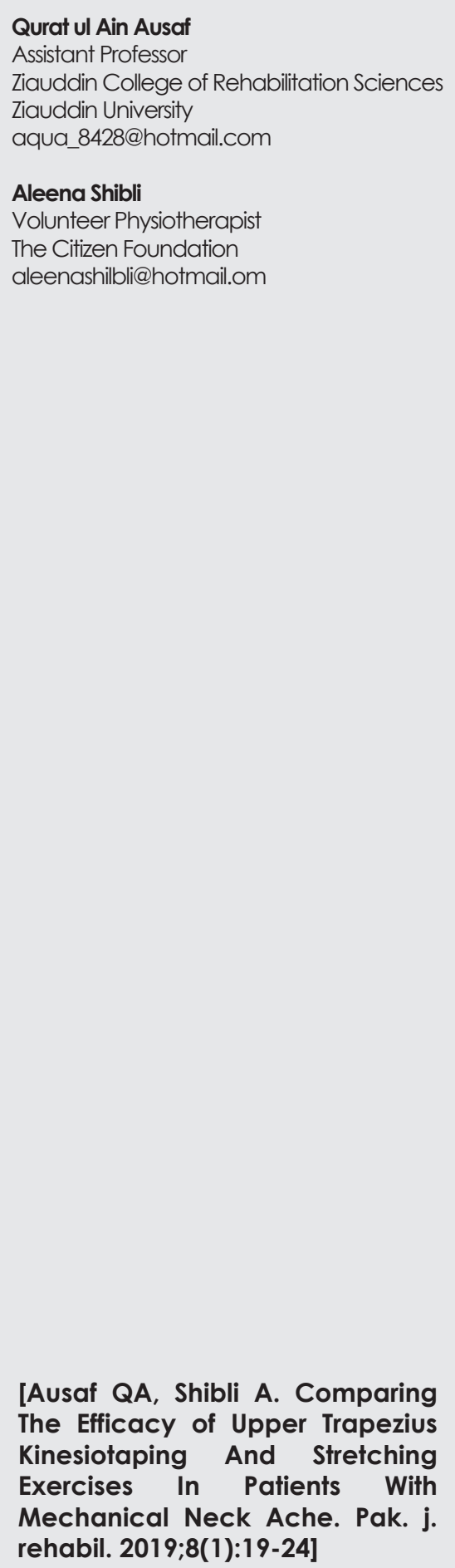

Qurat ul Ain Ausaf

Assistant Professor

Ziauddin College of Rehabilitation Sciences

Ziauddin University

The Citizen Foundation

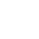




\section{INTRODUCTION}

The estimated prevalence of neck pain around the globe is one third of the population and is the 4th leading cause of disability'. Mechanical neck pain is a common musculoskeletal disorder in adult population, Approximately $26-71 \%$ of the adult population experience episodes of pain and decrease range of motion at neck ${ }^{2}$. Neck pain has a chronic recurring course, with significant percentage of individuals i.e. one-third of the population suffering from persistent neck pain annually'. It is revealed during the study of Hidalgo B in year 2017 that mostly people with Neck paindidnot recover completely, and symptoms may persists to some extent, in $50-85 \%$ cases recurrence occurs 1 to 5 years later ${ }^{3}$. Acute neck pain may resolve regardless of treatment, although half of the population continues to experience some degree of pain or reoccurrence of disability attributable to this condition ${ }^{4}$. Moloney $\mathrm{N}$ et al. and Lee Hopin et al in their studies has concluded that neck pain is commonly associated with activity restrictions $s^{5,6}$.

Mechanical neck ache has no definite cause; it is insidious in onset and can arise from numerous factors. Neither has it had neurological symptoms nor any known cause that the pain may arise from the inflamed facet joints and the degenerated disc ${ }^{7}$. Severe neck pain can results in self-reported disability and negative perception of health ${ }^{8}$.

The progression of inflammation leads to severe muscle spasm and eventually causes severe pain. In acute stages non-invasive treatment options are utilized for such cases. Numerous causes of cervical pain are associated with aging and they play major role in many degenerative conditions?

O'Riordan et al in 2014 concluded that utilizing a multimodal approach produces more beneficial effects in terms of increased strength, enhanced function, and health-related quality of life and reduced pain scores, because the clinical patterns of patients frequently do not respond to a single intervention, but there is increased probability of positive outcome with a multimodal approach 10 . Variety of treatment interventions are available for physical therapist now a days that include; manual therapy, comprising of joint mobilization and manipulations, set of therapeutic exercises for neck muscle strengthening and stretching with major emphasis on posture education. However, manipulation of the cervical spine carries some risk like ischemic stroke, cervical artery dysfunction or brain stem lesions ${ }^{11}$.

Greenstein Jay et al recommends physical therapy is the first line of treatment for neck ache and strong evidence advocate that manipulation or mobilization of cervical spine and exercises produces more effective results than other conservative treatment in long-term management of neck pain and stiffness'. Multiple studies have been conducted in recent past which has provided the numerous evidence in favor of physical therapy intervention and disability in cervical region ${ }^{12}$. Neck pain is commonly associated with activity limitations ${ }^{13}$.

In recent years, the use of KinesioTape (KT) has become immensely popular ${ }^{14}$. This method uses thin elastic tape ${ }^{15}$ which can be stretched up to $130-140 \%$ of its original length ${ }^{16}$. Nowadays; KT is broadly used in injury prevention and restoration of musculoskeletal disorders, and as backing methods for the treatment of fascia, muscles, or joints dysfunctions or even in lymphedema ${ }^{17}$. Multiple studies have proven that KT produces substantial favorable effect in reducing neck pain ${ }^{18}$. Application of KT expedites the pain relieving mechanism, at the same time it will provide support and stability to muscles and joints without minimizing the body's function. It is found to be effective in reducing pain, edema and muscular tightness, improves the range of motion (ROM), blood and lymphatic flow. It acts upon different receptors within the somatosensory system, relieves pain and enables lymphatic drainage by closely lifting the skin. This lifting affect forms convolutions in the skin resulting increasing interstitial space and allowing for a decrease in inflammation of the affected areas ${ }^{17}$.

Kinesiotaping was found to be effective when used in conjunction with isometric exercises of neck extensors and stretching exercises of levator scapulae, sternocleidomastoids and upper terapezius $^{19}$.

Many interventions are used in order to improve the mobility and stability of patients suffering from mechanical neck ache. The treatment plan may range from conventional stretching to modern kinesiotaping in this context many studies had been conducted in the past but only few trials were conducted to compare the effectiveness of stretching of trapezius and kinesiotaping. A study conducted by Ana Claudia in year 2008 concluded that different techniques of stretching in combination with manual therapy techniques were effective in improving neck pain, ranges and quality of life among females. It was suggested in the study that stretching exercises should be recommended as part of treatment regime in patients with chronic neck pain ${ }^{20}$. Effects of kinesiotaping and postural exercises have also been investigated on parameters on pain, NDI and upper trapezius activity in which it was observed that the effects of kinesiotaping are more effective in reducing pain and other outcome measures than postural exercises $^{21}$. Similar studies have also provided multiple evidences that the effects of exercises based physical therapy management are proven to be most effective in managing pain as a primary outcome measures along with the improvement of Range of motion in the level of the cervical region. Recently an interesting study has been conducted by BurcuMetinOkmen, in 2018 in which it was 
observed that eight week of strengthening exercises along with the application of TENS and therapeutic ultrasonic therapy are providing significant evidences in the management of chronic pain among cervical radiculopathy pain, moreover the same study also concluded that more researches are required in this regard to evaluate more significant results in this regard ${ }^{22}$.

According to Mansour Alotaibi et al in a meta-analysis conducted in 2018 it was concluded that exercises based physical therapy interventions included METs and kinesiotaping are providing significant results in the improvement of ROM, ODI and decreasing pain, however no study till date has been found to examine the effects of kinesiotaping alone in the management of neck pain ${ }^{23}$. Hence the present study is designed to evaluate the effects of kinesiotaping alone in the management of pain and to compare its effectiveness with other conventional based approach of physical therapy management in order to determine the time effective approach which could turn out to be beneficial for patient and proven to be evidently based physical therapy management protocol.

\section{METHODOLOGY}

\section{Study Design}

Randomized Controlled Trial

\section{Study Setting}

The study was conducted at Outpatient Physical Therapy Department of tertiary care hospital in Karachi.

\section{Duration of Study}

The study was conducted in the period of 6 months duration.

\section{Sample Size}

Sample of 68 participants were recruited for the study.

\section{Sampling technique \\ Envelop method was used.}

\section{Inclusion Criteria ${ }^{21,24}$}

- Patients aged between 18-40 years of both genders with primary complain of neck pain from one month or less, self-referred or referred by orthopedic physician.

- Patient with trigger points on upper trapezius.

- Patient with mechanical neck and shoulder pain provoked by giving pressure on upper trapezius.

\section{Exclusion criteria ${ }^{2}$}

- Patient with history of whiplash injury or any cervical injury, diagnosis of cervical radiculopathy, fibromyalgia, myelopathy.

- Patients with history of kinesiotape application or stretching exercise.

- Patients with history of vertebral artery insufficiency or any other serious co morbid.

\section{Data Collection Tools}

Data was collected at baseline and after treatment by using Numeric Pain Rating Scale for recording pain, Neck Disability Index for neck dysfunction and Manual Muscle Testing for measuring Upper trapezius strength.

\section{Procedure}

After taking informed consent, patients were allocated into two groups by randomization. Both groups were assessed at baseline and after treatment including neck assessment, muscle strength and Neck Disability index. Group A were treated with Moist Heat pack, Transcutaneous Electric Nerve Stimulation(TENS) and upper trapezius kinesiotaping whereas, group B were givenmoist heat pack, TENS and upper trapezius stretching. Each session comprised of 40-50 minutes. Both the groups were instructed to perform 15 minutes strengthening exercises taught by therapist twice on daily basis at home. A total of seven sessions were performed under the supervision of trained physical therapist on alternative days.

\section{GROUP A}

Hot pack were applied at cervical region and upper thoracic region for 20 minutes followed by application of TENS (asymmetrical biphasic pulsed) for 20 minutes. TENS were applied at upper trapezius muscle tender points ${ }^{26}$. Kinesiotape of $5 \mathrm{~cm}$ width was applied in form of $Y$ and I strip, these $Y$ strips covered the area from thoracic vertebrae of T3-T5 till base of occiput and I strip covered middle of neck in horizontal direction. The tape has been wear for 4 days if no allergic reactions were observed ${ }^{19}$.

\section{GROUP B}

Hot pack and TENS protocol was done similar to Group A. Patient were placed in supine position while therapist applied passive stretching technique at upper trapezius muscle. Position of participants was maintained, head in position of side bending, flexion and rotation toward the side to be stretched till the pain persist. Stretched position was maintained for 30 seconds. Repeat the stretch one more time ${ }^{26}$.

\section{Home Plan}

Home exercises plan were based on strengthening exercises of neck muscles. Participant were taught for isometric exercises of neck muscles i.e., extensors, flexors and side bending with 6 seconds hold with 5 time repetition of each exercise ${ }^{19}$.

\section{Data Analysis Procedure}

Data analysis was done using SPSS version 21. Mean and standard deviation were computed for quantitative variable i.e. age, height, weight, BMl, Pain intensity scale, Upper trapezius strength and Functional neck disability index. Frequency and percentage were calculated for qualitative variables i.e. gender.

Differences in Pain intensity scale, Upper trapezius 
strength and Functional neck disability index between group A and group B were compared by using independent $\dagger$ test. Mean comparison of pre and post were done by using paired t-test. $P$ value of $\leq 0.05$ was considered as significant.

\section{Ethical Consideration}

Following ethical issues were considered in this study: 1. Privacy and confidentiality statement was maintained for all participants.

2. Consent forms were obtained from participants to ensure that patient knows all of the risk and costs regarding the treatment.

3. Participants have the right to withdraw from the study at any time.

4. Consent from head of the department was taken for data collection in the hospital.

\section{RESULTS}

A randomized controlled trial was conducted on 68 participants that were randomly divided into two groups. The demographic details illustrated in figure $1,40 \%$ of the participants were female and $60 \%$ were male.

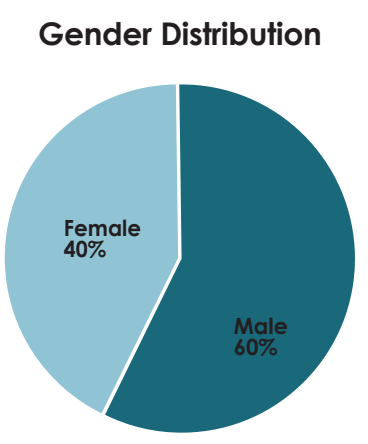

Figure 1. Gender Distribution

The baseline characteristics of the participants, mean age were $33.4 \pm 6.49$ and $32.09 \pm 6.40$ in kinesiotaping and stretching group respectively (table 1).

\begin{tabular}{|c|c|c|c|}
\hline \multicolumn{3}{|c|}{ Table 1 Baseline characteristic of the participants } \\
\hline Interventions & $\begin{array}{c}\text { Age } \\
\text { (years) }\end{array}$ & Height & Wt (kg) \\
\hline Kinesiotaping & $33.47 \pm 6.49$ & $5.43 \pm 0.31$ & $56.71 \pm 7.73$ \\
\hline Stretching & $32.09 \pm 6.40$ & $5.36 \pm 0.25$ & $56.68 \pm 7.37$ \\
\hline
\end{tabular}

Paired t test was applied to determine within the group comparison, the results revealed that 3 weeks of intervention strategies based on kinesiotapping and stretching were found to be significantly effective $p<0.05$ ( $95 \%$ of $\mathrm{Cl} ; \mathrm{a}=0.05$; two tailed statistics) in reducing pain among both groups (table $2)$. Both interventions were significantly effective $p$ $<0.05$ in improving upper trapezius muscles strength in both the groups as shown in the table 3 . The 3 weeks intervention was effective ( $\mathrm{p}$-value $<0.05$ ) in improving the neck disability index among the two groups (KT \& Stretching). (Table 4)

\begin{tabular}{|c|c|c|c|c|}
\hline \multicolumn{6}{|c|}{ Table 2. Mean value for \pm NPRS (Pre and Post) } \\
\hline \multirow{2}{*}{} & $\begin{array}{c}\text { Pre } \\
\text { NPRS } \\
\pm S D\end{array}$ & $\begin{array}{c}\text { POSt } \\
\text { NPRS } \\
\pm S D\end{array}$ & $\begin{array}{c}\text { Mean } \\
\text { Df }\end{array}$ & $\begin{array}{c}\text { P } \\
\text { value }\end{array}$ \\
\cline { 1 - 4 } KT & $\begin{array}{c} \pm .59 \pm 1 . \\
02\end{array}$ & $1.47 \pm 1.02$ & $\begin{array}{c}6.12 \pm \\
0.1\end{array}$ & $<0.05$ \\
\hline $\begin{array}{c}\text { Stretch } \\
\text { ing }\end{array}$ & $\begin{array}{c}7.50 \pm 1 . \\
05\end{array}$ & $2.41 \pm 1.10$ & $\begin{array}{c}5.09 \pm \\
0.05\end{array}$ & $<0.05$ \\
\hline
\end{tabular}

Table 3. Mean value for \pm Upper trapezius muscles strength (Pre and Post)

\begin{tabular}{|c|c|c|c|c|}
\hline $\begin{array}{c}\text { Interven } \\
\text { tion }\end{array}$ & $\begin{array}{c}\text { Pre M/S } \\
\text { Strength } \\
\pm S D\end{array}$ & $\begin{array}{c}\text { Post M/S } \\
\text { Strength } \\
\pm S D\end{array}$ & $\begin{array}{c}\text { Mean } \\
\text { Df }\end{array}$ & $\begin{array}{c}P \\
\text { value }\end{array}$ \\
\hline KT & $\begin{array}{c}2.91 \pm 0 . \\
67\end{array}$ & $4.50 \pm 0.51$ & $\begin{array}{c}1.59 \pm \\
0.16\end{array}$ & $<0.05$ \\
\hline $\begin{array}{c}\text { Stretchi } \\
\text { ng }\end{array}$ & $\begin{array}{c}2.41 \pm 1 . \\
10\end{array}$ & $3.03 \pm 0.58$ & $\begin{array}{c}0.62 \pm \\
0.52\end{array}$ & $<0.05$ \\
\hline
\end{tabular}

Table 4. Mean value for \pm Neck Disability index (Pre and Post)

\begin{tabular}{|c|c|c|c|c|}
\hline $\begin{array}{c}\text { Interven } \\
\text { tion }\end{array}$ & $\begin{array}{c}\text { Pre } \\
\text { NDI } \pm \text { SD }\end{array}$ & $\begin{array}{c}\text { Post } \\
\text { NDI } \\
\pm S D\end{array}$ & $\begin{array}{c}\text { Mean } \\
\text { differen } \\
\text { ce }\end{array}$ & $\begin{array}{c}P \\
\text { value }\end{array}$ \\
\hline $\mathrm{KT}$ & $\begin{array}{c}37.62 \pm 2 . \\
67\end{array}$ & $\begin{array}{c}9.00 \pm 2 . \\
71\end{array}$ & $\begin{array}{c}28.62 \pm 0 \\
.04\end{array}$ & $<0.05$ \\
\hline $\begin{array}{c}\text { Stretchi } \\
\text { ng }\end{array}$ & $\begin{array}{c}37.00 \pm 7 . \\
00\end{array}$ & $\begin{array}{c}14.06 \pm 5 \\
.23\end{array}$ & $\begin{array}{c}22.94 \pm 1 \\
.77\end{array}$ & $<0.05$ \\
\hline
\end{tabular}

Independent $\dagger$ test was applied to compare the results of kinesiotaping and stretching on numeric pain rate scale, manual muscle testing and Neck Disability Index. The post comparison of the two exercises regimes showed significant improvement $\mathrm{p}<0.05$ favoring both treatment options effective in the management of neck dysfunction but post mean showing that Kinesiotaping is more effective in improving pain, muscle strength and specifically neck disability illustrated in table 5.

\begin{tabular}{|l|c|c|c|c|}
\hline \multicolumn{5}{|c|}{ Table 5 showing between two group analysis } \\
\hline & $\begin{array}{r}\text { KT post } \\
\text { mean }\end{array}$ & $\begin{array}{c}\text { Stretching } \\
\text { Post Mean }\end{array}$ & $\begin{array}{c}\text { Mean } \\
\text { df }\end{array}$ & $\begin{array}{c}\text { P - } \\
\text { value }\end{array}$ \\
\hline NPRS & $1.47 \pm 0.99$ & $2.41 \pm 0.99$ & $\begin{array}{c}0.94 \pm \\
0.08\end{array}$ & $<0.05$ \\
\hline & & & $0.79 \pm$ & $<0.05$ \\
MMT & $4.50 \pm 0.49$ & $3.71 \pm 0.66$ & 0.16 & \\
\hline \multirow{2}{*}{ NDI } & $9.06 \pm 2.65$ & $14.19 \pm 5.20$ & $\begin{array}{c}5.13 \pm \\
2.55\end{array}$ & $<0.05$ \\
& & & & \\
\hline
\end{tabular}




\section{DISCUSSION}

The study was conducted to compare the effects of kinesiotaping and stretching exercises on pain scale, upper trapezius muscle strength and neck disability index in patients with mechanical neck ache. The results of current study revealed that both interventions are effective in improving muscle strength and decreasing the pain scale on numeric pain rating scale. Further the results obtained during the course of analysis revealed that the effects of kinesiotaping in improving pain, neck disability index (NDI) and muscle strength were more significant when compared with stretching exercises. The results were according to results of the study conducted by Amira $M$ el Gendy et al, in which the author concluded that kinesiotaping were not only effective in improving pain scale, NDI and muscle strength, it also improves the cervical range of motion after six weeks of intervention study how ever authors interestingly concluded that the maximum effects were obtained within a week of intervention ${ }^{23}$.

In another study conducted in the year by Ali et al, it was concluded that a significant improvement in the pain, NDI and CROM was recorded in the group that were given intervention using kinesiotaping strategy with physical therapy treatment protocols ${ }^{19}$.

After the application of kinesiotape greater improvement is reported in neck pain as compared to group treated with stretching. Similar results were obtained from the previous studies in which pain scale and cervical range of motion was observed, the study revealed an improvement in both the parameters immediately after the application of kinesiotape on cervical region ${ }^{27}$.

Pain relieving effects of kinesiotaping can be obtained by pain inhibition mechanism and facilitation of blood flow to the targeted muscles. A Study conducted by Al Shareefet all in 2016 on nonspecific low back pain also concluded that kinesiotaping application for two weeks was effective in improving pain and trunk flexion; it was also effective in reducing disability related to low back pain ${ }^{28}$. Moreover the author also suggested that Kinesiotaping methods should be studied with various other treatment protocols as an adjunct therapy.

Various researches conducted in the recent past favored the effects of kinesiotaping in relieving pain and improving the functional ability of the patients with the neck pain but all those study were using kinesiotaping in addition with some other physical therapy management approaches but none of the study has identified the impact kinesiotaping alone in the management of neck related problems. Further the role of neck muscular strength were also not highlighted in previous studies as per author believe that present study is first of its type that was conducted to determine the impact of two different physical therapy intervention that were kinesiotaping and stretching in the management of neck pain and improve the muscular strength. The study has some limitations that like the data were collected from a single tertiary care hospital of Karachi with a sample size of 68 and author recommends that more studies with larger sample size should be conducted in order to generalize the findings of the study. Further the study was only confined to pain, strength and NDI questionnaire the impact of interventional strategies on cervical ROM is beyond the scope of the study29. Follow up for this study was not observed hence future researches should be conducted to observe the long term effects of kinesiotaping on various parameters.

\section{CONCLUSION}

Our study concluded that kinesiotaping combined with conventional physical therapy treatment was more effective in improving neck pain, upper trapezius muscle strength and functional disability (NDI) than upper trapezius stretching exercises. However, in order to determine the residual effects, further follow up studies will be required to conduct in the field.

\section{REFERENCES}

[1] Greenstein J, McNamara T, Bishop B, Etnoyer-Slaski J, Topp R. The Effect of Kinesiology Tape on Pain and Neck Range of Motion after Cervical Manipulation. Journal of performance Health research. 2017 1; (1).

[2] Vos T, Flaxman AD, Naghavi $M$, Lozano R, Michaud C, Ezzati $M$, Shibuya K, Salomon JA, Abdalla S, Aboyans V, Abraham J. Years lived with disability (YLDs) for 1160 sequelae of 289 diseases and injuries 1990-2010: a systematic analysis for the Global Burden of Disease Study 2010. The lancet. 2012;380(9859):2163-96.

[3] Hidalgo B, Hall T, Bossert J, Dugeny A, Cagnie B, Pitance L. The efficacy of manual therapy and exercise for treating non-specific neck pain: A systematic review. Journal of back and musculoskeletal rehabilitation. 2017;30(6):1 149-69.

[4] Cohen SP. Epidemiology, diagnosis, and treatment of neck pain. InMayo Clinic Proceedings Elsevier 2015;90(2):284-299.

[5] Moloney N, Rebeck T, Azoory R, Huebscher M, Waller R, Beales D. Do measures of pain sensitivity predict pain and disability at 1-year follow up in people with chronic neck pain?. Manual Therapy. 2016;100(25):e39-40.

[6] Lee H, Hübscher M, Moseley GL, Kamper SJ, Traeger AC, Mansell G, McAuley JH. How does pain lead to disability? A systematic review and meta-analysis of mediation studies in people with back and neck pain. Pain. 2015;156(6):988-97.

[7] Bier JD, Scholten-Peeters WG, Staal JB, Pool J, van Tulder MW, Beekman E, Knoop J, Meerhoff G, Verhagen AP. Clinical practice guideline for physical therapy assessment and treatment in patients with nonspecific neck pain. Physical therapy. 
2017:98(3):162-71.

[8] Dimitriadis Z, Kapreli E, Strimpakos N, Oldham J. Do psychological states associate with pain and disability in chronic neck pain patients?. Journal of back and musculoskeletal rehabilitation. 2015;28(4):797-802.

[9] Naser SS, ALmursheidi SH. A Knowledge Based System for Neck Pain Diagnosis. World Wide Journal of Multidisciplinary Research and Development (WWJMRD). 2016;2(4):12-8.

[10] O'Riordan C, Clifford A, Van De Ven P, Nelson J. Chronic neck pain and exercise interventions: frequency, intensity, time, and type principle. Archives of physical medicine and rehabilitation. 2014;95(4):770-83.

[11] Langenfeld A, Humphreys BK, de Bie RA, Swanenburg J. Effect of manual versus mechanically assisted manipulations of the thoracic spine in neck pain patients: study protocol of a randomized controlled trial. Trials. 2015;16(1):233.

[12] Wong JJ, Shearer HM, Mior S, Jacobs C, Côté P, Randhawa K, YU H, Southerst D, Varatharajan S, Sutton D, van der Velde G. Are manual therapies, passive physical modalities, or acupuncture effective for the management of patients with whiplash-associated disorders or neck pain and associated disorders? An update of the Bone and Joint Decade Task Force on Neck Pain and Its Associated Disorders by the OPTIMa collaboration. The Spine Journal. 2016;16(12):1598-630.

[13] Kalron A, Bar-Sela S. A systematic review of the effectiveness of Kinesio Taping--fact or fashion. Eur J PhysRehabil Med. 2013;49(5):699-709.

[14] Gomez-Soriano J, Abián-Vicén J, Aparicio-García C, Ruiz-Lázaro P, Simón-Martínez C, Bravo-Esteban E, Fernández-Rodríguez JM. The effects of Kinesio taping on muscle tone in healthy subjects: a double-blind, placebo-controlled crossover trial. Manual therapy. 2014;19(2):131-6.

[15] Parreira PD, Costa LD, Junior LC, Lopes AD, Costa LO. Current evidence does not support the use of Kinesio Taping in clinical practice: a systematic review. Journal of physiotherapy. 2014;60(1):31-9.

[16] Halski T, Ptaszkowski K, Słupska L, Paprocka-Borowicz M, Dymarek R, Taradaj J, Bidzińska G, Marczyński D, Cynarska A, Rosińczuk J. Short-term effects of kinesio taping and cross taping application in the treatment of latent upper trapezius trigger points: a prospective, single-blind, randomized, sham-controlled trial. Evidence-based complementary and alternative medicine. 2015.

[17] Guner S, Alsancak S, Koz M. Effect of two different kinesio taping techniques on knee kinematics and kinetics in young females. Journal of physical therapy science. 2015;27(10):3093-6.

[18] Lee H, Hübscher M, Moseley GL, Kamper SJ, Traeger AC, Mansell G, McAuley JH. How does pain lead to disability? A systematic review and meta-analysis of mediation studies in people with back and neck pain. Pain. 2015;156(6):988-97.

[19] Ali MF, EL-WARDANY SH, Alduraibi SK. Effect of kinesio taping in patients with mechanical neck dysfunction. Med J Cairo Univ. 2015;83:867-73.

[20] Alotaibi M, Ayoub A, King T, Uddin S. The effect of kinesio taping in reducing myofascial pain syndrome on the upper trapezius muscle: a systematic review and meta-analysis. European Scientific Journal. 2018;28(14):6.

[21] Teodori RM, Negri JR, Cruz MC, Marques AP. Global Postural Re-education: a literature review. Brazilian Journal of Physical Therapy/Revista Brasileira de Fisioterapia. 2011 May 1;15(3).

[22] Elabd A, Ibrahim A, Elhafez H. Kinesio taping versus postural correction exercises on mechanically triggered neck dysfunction. Int $J$ Rehabil Res. 2017;24(4):155-62.

[23] Ökmen BM, Ökmen K, Altan L. Investigation of the effectiveness of therapeutic ultrasound with high-resolution ultrasonographic cross-sectional area measurement of cervical nerve roots in patients with chronic cervical radiculopathy: a prospective, controlled, single-blind study. Journal of Medical Ultrasonics. 2018;45(3):479-86.

[24] El-Gendy AM, Ali OI, Hamada HA, Radwan R. Effect of kinesio taping on chronic mechanical neck pain: a randomized controlled trial. Bulletin of Faculty of Physical Therapy. 2018;23(2):101.

[25] Saavedra-Hernández M, Castro-Sánchez AM, Arroyo-Morales M, Cleland JA, Lara-Palomo IC, Fernandez-De-Las-Penas $C$. Short-term effects of kinesio taping versus cervical thrust manipulation in patients with mechanical neck pain: a randomized clinical trial. J. Orthop. Sports Phys. Ther. 2012;42(8):724-30.

[26] Dissanayaka TD, Pallegama RW, Suraweera HJ, Johnson MI, Kariyawasam AP. Comparison of the effectiveness of transcutaneous electrical nerve stimulation and interferential therapy on the upper trapezius in myofascial pain syndrome: a randomized controlled study. Am J Phys Med Rehabil. 2016;95(9):663-72.

[27] Hanney WJ, Puentedura EJ, Kolber MJ, Liu X, Pabian PS, Cheatham SW. The immediate effects of manual stretching and cervicothoracic junction manipulation on cervical range of motion and upper trapezius pressure pain thresholds. J Back Musculoskelet Rehabil. 2017;30(5):1005-13.

[28] Paoloni M, Bernetti A, Fratocchi G, Mangone M, Parrinello L, Del Pilar Cooper M, Sesto L, Di Sante L, Santilli $\vee$. Kinesio Taping applied to lumbar muscles influences clinical and electromyographic characteristics in chronic low back pain patients. Eur J Phys Rehabil Med. $2011 ; 47(2): 237-44$.

[29] Al-Shareef AT, Omar MT, Ibrahim AH. Effect of kinesio taping on pain and functional disability in chronic nonspecific low back pain. Spine. 2016:41(14):821-8. 